Article

\title{
Experimental Study on the Mechanical Behavior of EN08 Steel at Different Temperatures and Strain Rates
}

\author{
Farid Abed ${ }^{1,2, *} \mathbb{D}$, Akrum Abdul-Latif ${ }^{3,4}$ and Ayatollah Yehia ${ }^{1}$ \\ 1 Department of Civil Engineering, American University of Sharjah, Sharjah 26666, UAE; \\ g00056122@alumni.aus.edu \\ 2 Material Science and Engineering Institute, American University of Sharjah, Sharjah 26666, UAE \\ 3 Laboratoire Quartz, Supméca, 3, rue Fernand Hainaut, 93407 St Ouen CEDEX, France; \\ abdul-latif@iu2t.univ-paris8.fr \\ 4 Université Paris 8, IUT de Tremblay, 93290 Tremblay-en-France, France \\ * Correspondence: fabed@aus.edu; Tel.: +971-6515-2493
}

Received: 17 August 2018; Accepted: 17 September 2018; Published: 19 September 2018

\begin{abstract}
The objective of this paper is to investigate the mechanical response of EN08 steel at quasi-static and dynamic strain rates. Uniaxial tensile tests under quasi-static regime (from $0.0015 \mathrm{~s}^{-1}$ to $0.15 \mathrm{~s}^{-1}$ ) are conducted on EN08 steel at a range of temperatures between $298 \mathrm{~K}$ and $923 \mathrm{~K}$. Dynamic compression tests are also performed by using a drop hammer and by considering different masses and heights to study the material response at strain rates up to $800 \mathrm{~s}^{-1}$. Through the stress-strain responses of EN08 steel, a strong dependency of the yield stress as well as the ultimate strength on the strain rate and temperature is recognized. Furthermore, the strain hardening is highly affected by the increase of temperature at all levels of strain rate. The microstructure of the steel is also examined at a fracture by using SEM images to quantify the density of microdefects and define the damage evolution by using an energy-based damage model.
\end{abstract}

Keywords: EN08 steel; mechanical behavior; temperature; strain rate; damage

\section{Introduction}

Steel, with its uses in various industrial applications, has had its behavior studied at different temperatures and strain rates. Many researchers have experimentally quantified the parameters controlling the thermomechanical behavior of steel [1-5] including its damage mechanisms [6-9].

As a medium, carbon steel is known for its tensile strength and toughness [10,11] and EN08 steel is widely used for manufacturing mechanical parts such as general-purpose axels, shafts, bolts, gears, and studs. The microstructure of EN08 varies depending on the designed heat treatment [10]. Zarroug et al. [12] tested EN08 steel under combined torsion-tension loading where the specimens were loaded either by maintaining a constant tensile load (or a constant axial displacement) and increasing torque (or twist angle) or by maintaining a constant torque (or a constant twist angle) and increasing the tensile load (or axial displacement). The authors concluded that, when the torsion angle is kept constant with an increasing axial load, the carrying capacity of the torque drops rapidly as soon as the yield strength is reached. Moreover, for maintaining the applied load on the successive application of torque, the axial strain increases with the shear strain. For higher load cases, the axial stress can be rapidly increased.

Haque and Hashmi [13] studied the stress-strain behavior of EN08 steel at various strain rates and at temperatures between $-30^{\circ} \mathrm{C}$ and $235^{\circ} \mathrm{C}$. A strong sensitivity to strain rates between 103 and $105 \mathrm{~s}^{-1}$ was recognized for EN08 steel at various temperatures. This sensitivity, however, decreases with the increase in the strain rate at a range of temperatures between $30{ }^{\circ} \mathrm{C}$ and $235^{\circ} \mathrm{C}$. It was 
observed that the stress values at $235^{\circ} \mathrm{C}$ were almost equal to those obtained at room temperature under quasi-static compression. On the other hand, at $235^{\circ} \mathrm{C}$, the stress values were lower than those obtained at room temperature for higher strain rates [13].

At an elevated temperature, one of the important considered factors is the effect of holding time (exposure time) on some metallurgical features of metals like recrystallization or grain growth, which leads to a grain size effect on the metal response. It is well-known that certain heat treatments like aging control of the second-phase particles coarsen significantly by affecting the mechanical behavior of material. The interaction between the elevated temperature and the strain rate reveals a key effect on the metal response. Accordingly, high-temperature strength should be considered with respect to time since it becomes highly dependent on the strain rate. This dependence of strength becomes important in different materials at different temperatures [14-16].

Most of the previous research on EN08 focused on characterization and microstructure improvements of this material to obtain better mechanical properties. However, the literature lacks research related to investigating the damage evolution coupled with plasticity for this steel at elevated temperatures. Therefore, this research aims to study the mechanical response of EN08 steel under different combinations of temperatures and strain rates in an attempt to provide more insight about its coupled damage-plasticity response. The nature of this response is crucial in several applications in civil and mechanical engineering for improving safety against blast loads, impacts, and crushes.

\section{Experimental Results and Discussions}

The experimental program conducted in this work provides significant results regarding the description of the thermo-mechanical behavior for the EN08 steel at different loading conditions. Table 1 illustrates the chemical composition of the tested material.

Table 1. Chemical composition of EN08 specimens.

\begin{tabular}{ccccccc}
\hline Chemical Composition & C & Mn & Si & Al & Sr & Fe \\
\hline EN08 & 0.41 & 0.6 & 0.3 & 0.2 & 0.2 & balance \\
\hline
\end{tabular}

\subsection{Quasi-Static Tests at Room and High Temperatures}

A set of coupon specimens was manufactured and tested at different initial temperatures. The specimens followed the ASTM standards, which is shown in Figure 1a except for a modification in the gauge length. It was shortened to attain higher strain rates. A universal testing machine with a 100-kN capacity was employed for the uniaxial tensile tests along with a Zwick/Roell 3-zone high temperature furnace (Zwick/Roell, Ulm, Germany), which is shown in Figure 1b. A furnace controller was used to maintain the temperature within $\pm 1{ }^{\circ} \mathrm{C}$ of the specified experimental temperature.

Tensile tests were conducted at room temperature (i.e., $298 \mathrm{~K}$ ) as well as at three selected high temperatures of $523 \mathrm{~K}, 723 \mathrm{~K}$, and $923 \mathrm{~K}$. For each initial temperature, the specimens were tested at two different quasi-static strain rates of $0.0015 \mathrm{~s}^{-1}$ and $0.15 \mathrm{~s}^{-1}$ except for the room temperature where a third strain rate of $0.015 \mathrm{~s}^{-1}$ was considered. The obtained stress-strain data were recorded and converted into true stress-true strain curves, as illustrated in Figures $2-4$. The results represent average values of two or three specimens for each test condition.

Figure 2 shows that, at room temperature, the yield and ultimate stresses increase with increases in the strain rate. Note that this is a typical trend of steel. It is evident from this figure that the yield stress of the material cannot be identified due to the existence of an ambiguous yield region. Therefore, the yield stress was taken at a $0.2 \%$ offset point. It can also be observed that the trend of strain hardening is independent of the strain rate and the main difference is due to the initial yield. This indicates that the quasi static response of this material at room temperature is similar to the response of BCC metals where the flow stress is mainly controlled by the yield stress and nearly independent of the plastic 
strain rate [17]. The change in the yield stress with a strain rate may be interpreted physically since the resistance of initial dislocations by the Peierls barriers is provided by the lattice itself [18].

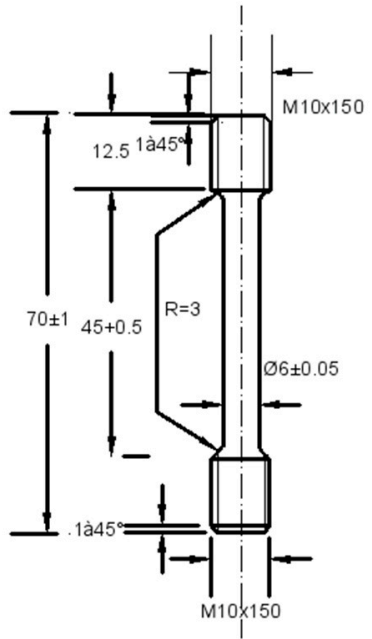

(a)

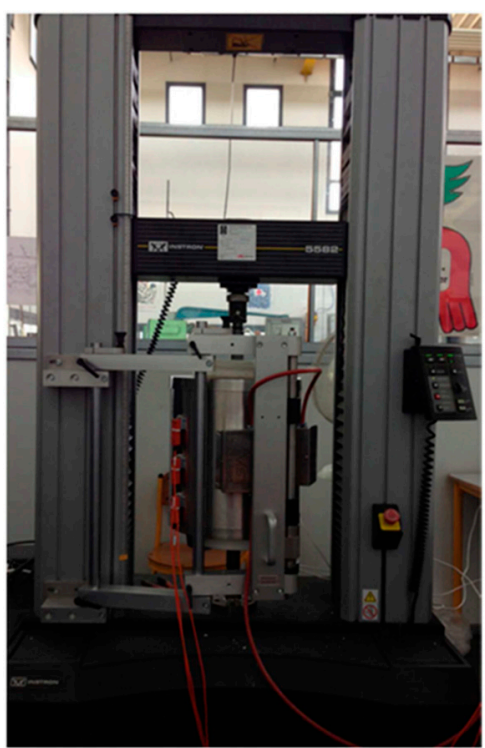

(b)

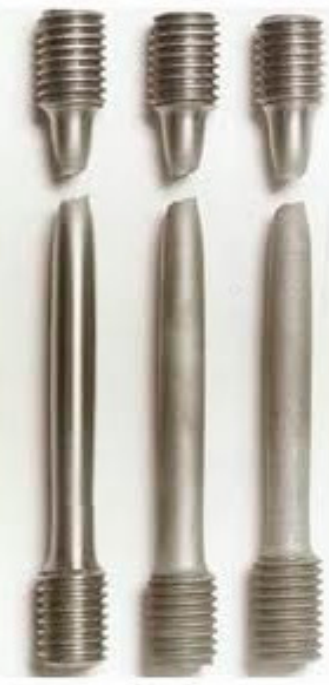

(c)

Figure 1. (a) Dimensions (in mm) of the coupon specimens, (b) UTM machine with Zwick/Roell 3-zone high temperature furnace, and (c) failure modes at high temperatures.

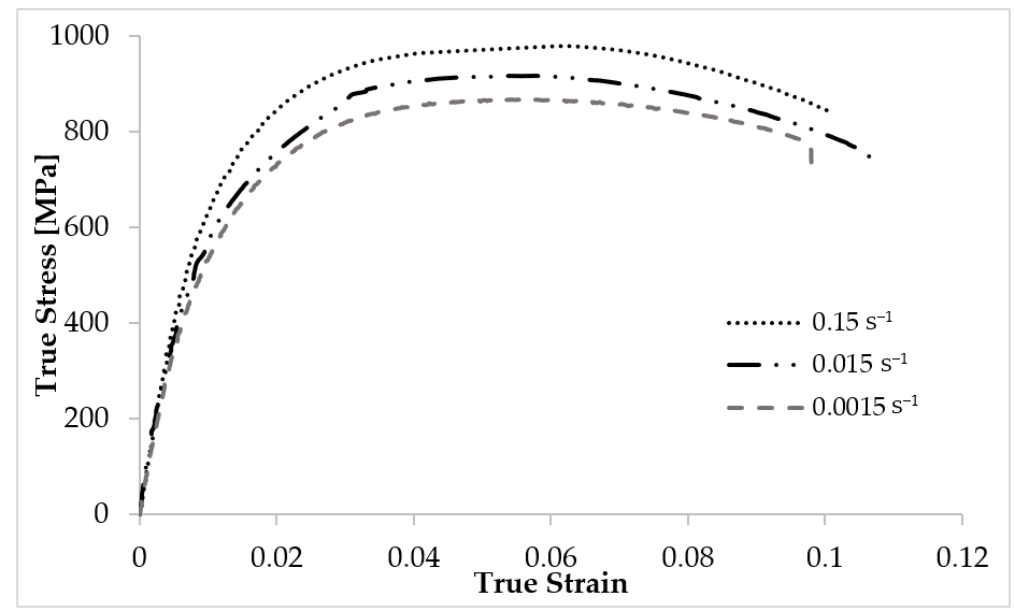

Figure 2. True stress-strain curves at room temperature and various strain rates.

Figures 3 and 4 show the steel's behavior at three high temperatures (523 K, $723 \mathrm{~K}$, and $923 \mathrm{~K})$ under two different quasi-static strain rates of $0.15 \mathrm{~s}^{-1}$ and $0.0015 \mathrm{~s}^{-1}$, respectively. To obtain these results, the UTM machine and the Zwick/Roell 3-zone high temperature furnace were utilized in which the furnace was controlled independently. The universal 3-zone furnace controller (model ME44-180) was used to maintain the temperature within $\pm 1{ }^{\circ} \mathrm{C}$ of the specified experiment temperature. For each zone, a thermocouple of $\mathrm{Ni} / \mathrm{CrNi}$ was available in the furnace. Three thermocouples were also mounted on the sample. To perform the test, the samples and load train were placed within the upper and lower cover plates. The test legitimately began once the specimens were exposed to heat and the three thermocouples located at the top, middle, and bottom of the gauge length gave readings with a difference not exceeding $\pm 3{ }^{\circ} \mathrm{C}$ of the required temperature. This initial difference in temperature readings could have contributed to the failure modes for most tensile specimens where the location of necking was near one of the ends, which is shown in Figure 1c. 


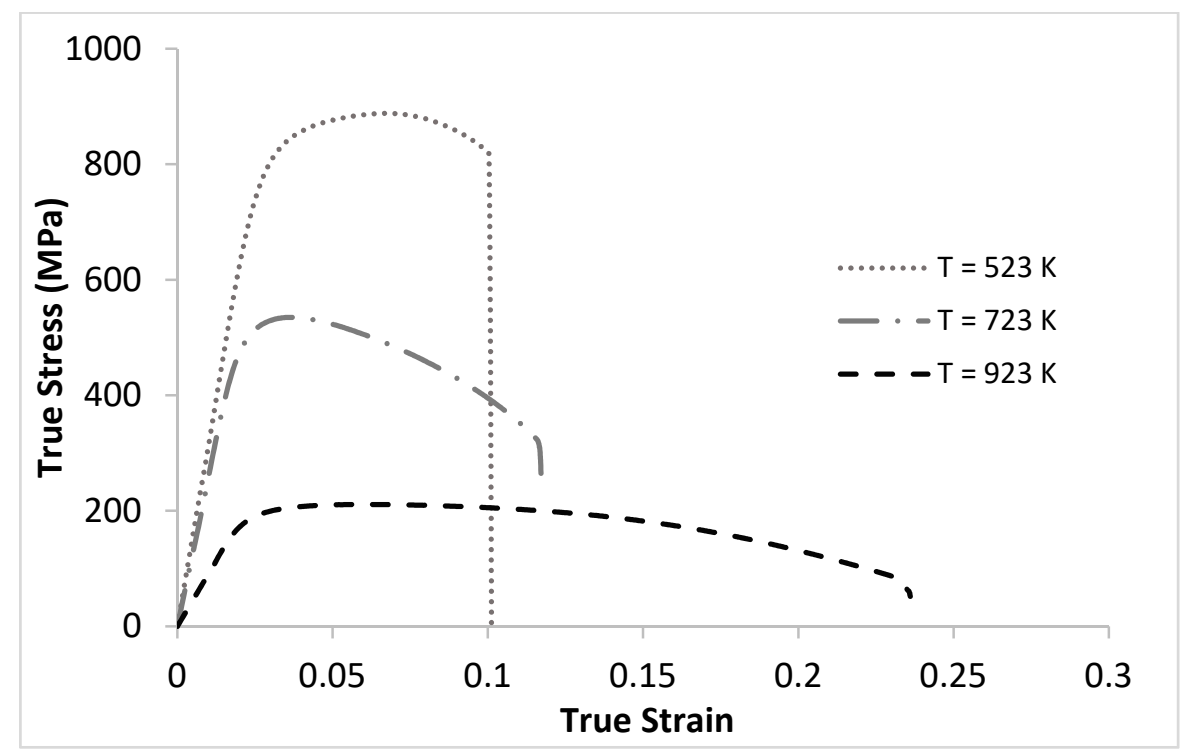

Figure 3. True stress-strain curves at high temperatures at a strain rate of $0.0015 \mathrm{~s}^{-1}$.

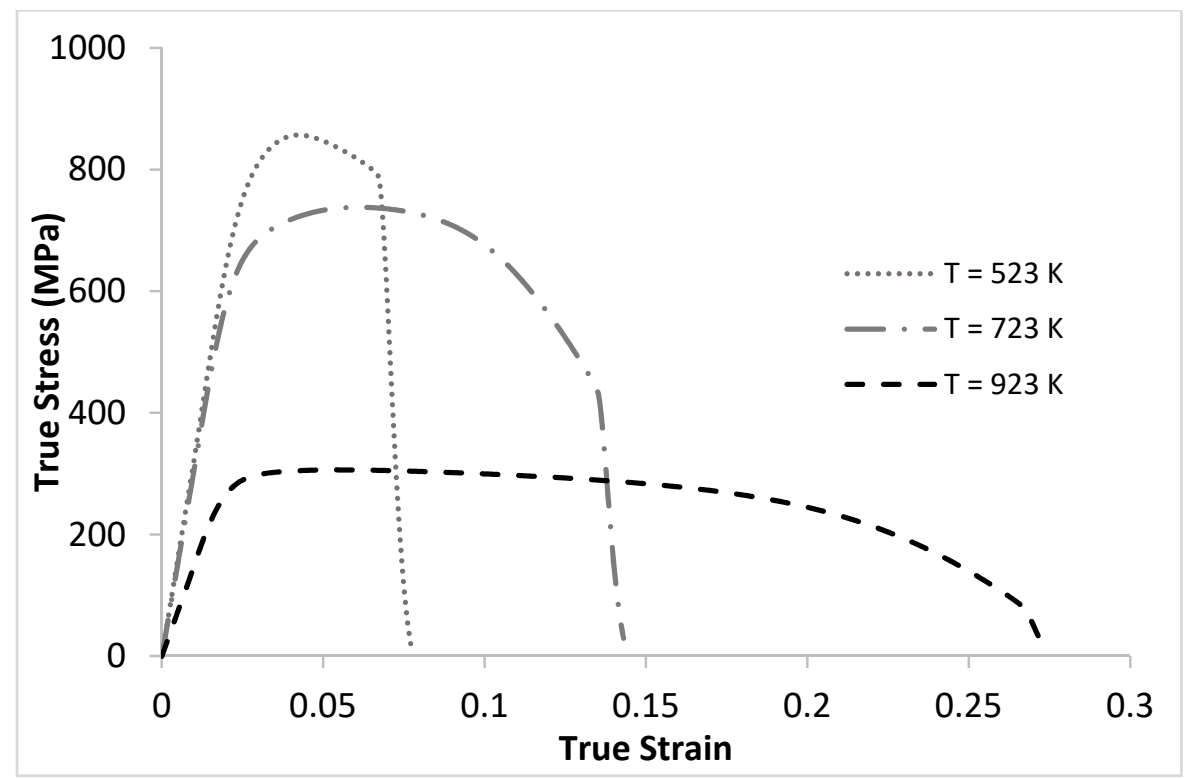

Figure 4. True stress-strain curves at high temperatures at a strain rate of $0.15 \mathrm{~s}^{-1}$.

For a given strain rate, yield stress decreases as temperature increases, which is shown in Figure 3 for $0.0015 \mathrm{~s}^{-1}$ and in Figure 4 for $0.15 \mathrm{~s}^{-1}$. The initial stiffness is almost the same at temperatures $523 \mathrm{~K}$ and $723 \mathrm{~K}$ regardless of the applied strain rate. However, it decreases at the highest temperature, i.e., $923 \mathrm{~K}$. As far as the plastic region is concerned, strain hardening diminishes completely at temperatures beyond $523 \mathrm{~K}$ where the softening phenomenon occurs immediately after the yield strength and where its evolution becomes steeper due to damage-significant evolution. This indicates that there is no strain hardening and that only athermal stresses remain. It can be deduced from the above stress-strain results that the flow stress of EN08 steel follows the same trend of the most ferrite steel where the yield stress becomes dependent on temperature and strain rate while the strain hardening is mainly related to the athermal part of the flow stress [19].

The thermomechanical response of the EN08 alloy is further investigated by studying the degradation trend of its flow stress with temperatures shown in Figure 5 for the lower and higher quasi-static strain rates considered. In general, the yield and ultimate tensile strengths of metals 
decrease with an increasing temperature. This is due to several factors such as a rapid increase in the atoms mobility, a greater mobility of dislocations based on the climb mechanism, the impact of diffusion-controlled processes particularly at a high temperature, and the increase of equilibrium concentration of vacancy. Thus, the deformation mechanisms could be changed at an elevated temperature where the activated slip systems change and/or additional activated slips come into play. Likewise, the higher the temperature, the greater is the possibility of deformation of grain boundaries.

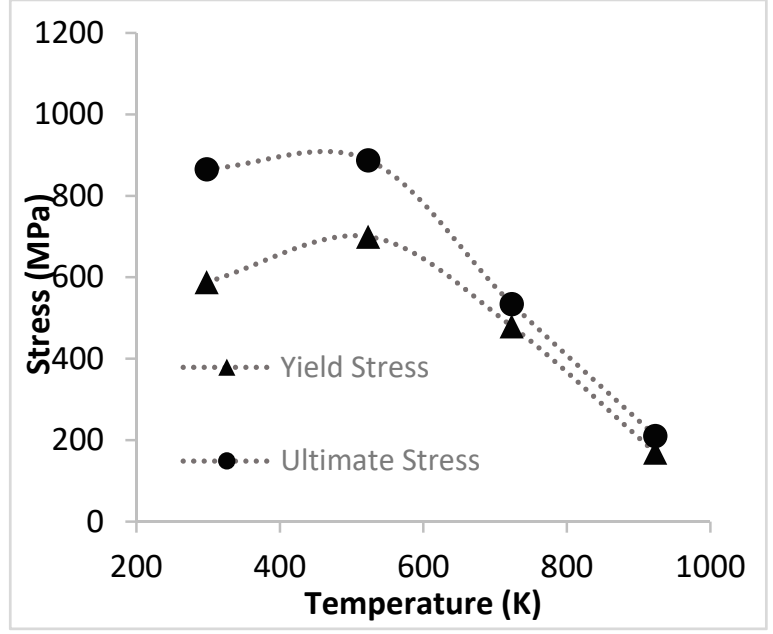

(a)

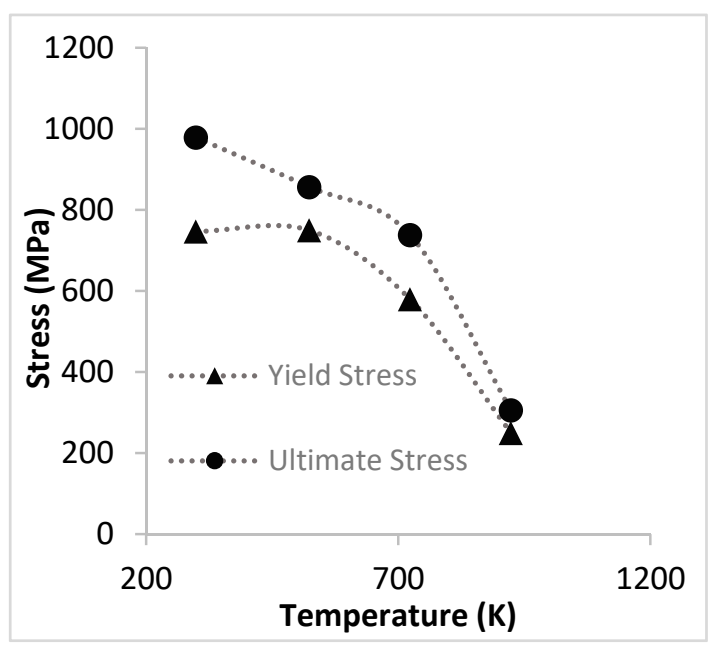

(b)

Figure 5. Stress variations with temperature at a strain rate of (a) $0.0015 \mathrm{~s}^{-1}$ and (b) $0.15 \mathrm{~s}^{-1}$.

The trend of the flow stress seems to be slightly different between the two quasi-static rates where it becomes steeper at $523 \mathrm{~K}$ for the low rate (Figure $5 \mathrm{a}$ ) and at $723 \mathrm{~K}$ for the higher strain rate (Figure $5 \mathrm{~b}$ ). In addition, the variation of the flow stress with a temperature does show abnormal jumps at the lower strain rate (Figure 5a), which indicates an existence of dynamic strain aging (DSA). This phenomenon, however, starts disappearing at the higher strain rate (Figure 5b). The DSA phenomenon, which is an occurrence happening when diffusing solute atoms and mobile dislocations that interact in the material $[20,21]$, generally occurs in high strength ferrite and austenite steel at a specific combination of temperatures and strain rates [22].

\subsection{Drop-Hammer Test}

All the dynamic tests were experimentally carried out at room temperature by utilizing a dynamic drop mass bench of a maximum impact velocity of $10 \mathrm{~m} / \mathrm{s}$ and a maximum kinetic energy of $2.5 \mathrm{~kJ}$. The specimens were placed on a bench with a free end from the top and slightly gripped from the bottom by using very soft materials (artificial clay). The bench is equipped with a dynamic load cell of $20 \mathrm{t}$, a $5000 \mathrm{~g}$ accelerometer, and a laser beam displacement transducer (series M5L of international Bullier, Nanterre, France) for a measurement bracket of $100 \mathrm{~mm}$. These instruments were connected to a rapid acquisition chain $(2.5 \mathrm{MHz})$, which ensured the simultaneous recording of the following experimental data: force, acceleration, and displacement. To ensure the synchronization of the acquisition of these essential data, two photocells were used. For the suitability of the collected experimental data, the positioning of these photocells was important and depended on the striker position just before the impact. Steel samples were tested by using the drop hummer where the potential energy transforms to kinetic energy. The falling mass strikes the sample at a specified velocity. The recording data especially the impact force will need to go through a filtering process by using the so-called Chebyshev filter. The inertial effect is assumed negligible since the impact velocities are relatively low (lower than $30 \mathrm{~m} / \mathrm{s}$ ). EN08 cylindrical samples of $12 \mathrm{~mm}$ long and a $6 \mathrm{~mm}$ diameter were used. The samples were tested using three different masses of $17.0 \mathrm{~kg}, 22.0 \mathrm{~kg}$, and $34.6 \mathrm{~kg}$ with each at a different height of $4 \mathrm{~m}, 3 \mathrm{~m}$, and $2 \mathrm{~m}$, respectively, to determine comparable kinetic energies. The corresponding strain rates $(\dot{\varepsilon})$ 
( $\dot{\varepsilon}=v / l$ with $l=\left(l_{0}+l_{f}\right) / 2$, where $l_{o}$ is the specimen initial length and $l_{f}$ is the specimen final length) are $885 \mathrm{~s}^{-1}, 767 \mathrm{~s}^{-1}$, and $620 \mathrm{~s}^{-1}$, respectively. The stress and strain are computed by using the force and displacement recorded by the machine's instruments.

Therefore, the axial stress and axial strain are computed through the filtered impact force and displacement and converted into true stress and true strain, respectively, which is shown in Figure 6, for the three loading scenarios. It is hard to identify a clear yield point for this material and its flow stress behavior at this test setup. With almost the same energy applied, the dynamic response of the material at the three different dynamic strain rates showed almost similar trends but with a slight increase in its ultimate stress when the strain rate increased. However, the ultimate stress achieved with the drop hammer test is higher than the one reached with the quasi-static test.

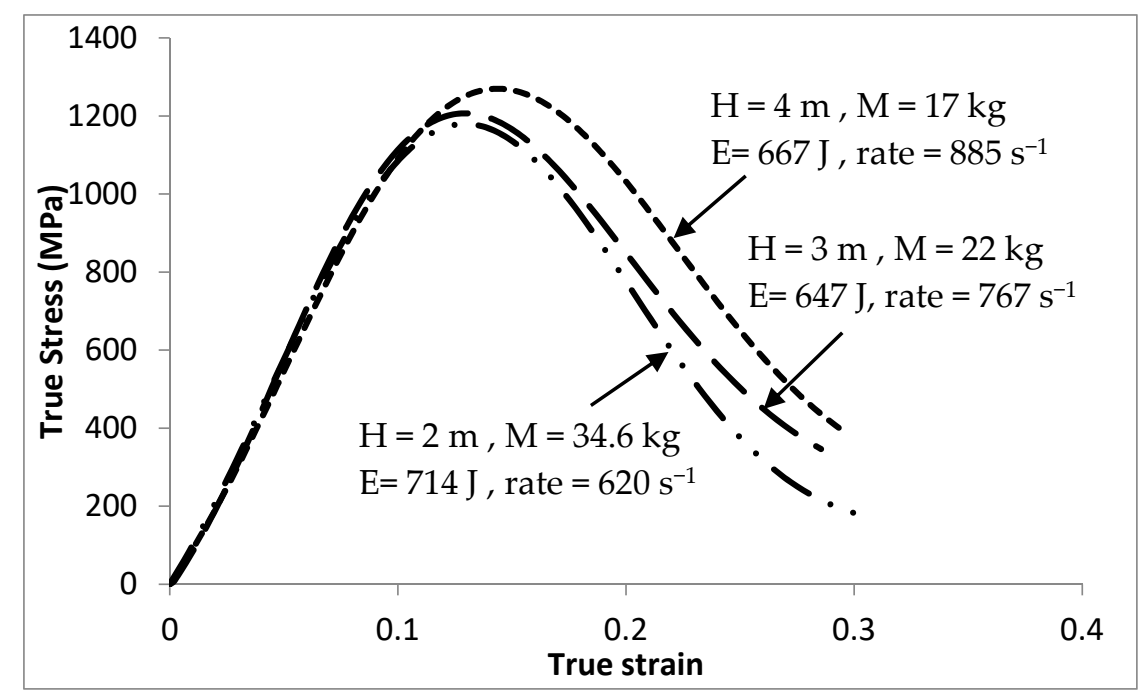

Figure 6. True stress-true strain curves from the drop-hammer tests at various masses and heights.

The drop hammer tests may give an indication on the increase in the ultimate stresses when compared with the tensile tests but only for the room temperature condition. The objective was also to evaluate the damage and show the increase with a strain rate. However, SEM images of drop-hammer specimens were not representatives, which is explained next.

\subsection{Scanning Electron Microscope (SEM)}

To understand the thermo-mechanical behavior of a metal, the microstructure of the material should be studied at failure. Internal damage generated by various combinations of loading rates and temperatures includes void nucleation, growth, and coalescence. These forms of damage are concentrated in regions near the fracture surface where the phenomenon of plastic localization is clearly observed via the specimen necking. In such regions, the plastic strains and their accompanying stresses are at a maximum (Figure 1c). The Scanning Electron Microscopy (SEM, XL30, Eindhoven, The Netherlands) is a current image analysis tool that can measure the damaged areas as interpreted micro-graphs and produce information for qualitative and quantitative analysis.

In this study, each sample was polished with coarse and fine-grained sandpaper as well as with diamond dust. A well-known process for SEM sample preparation was followed in order to have a clear fractured surface without changing the mechanical property of the samples by erasing the cracks inside the samples or even causing any further cracks. Samples were also processed using a backscatter electron detector in order to obtain an accurate percentage of the damaged area. Figure 7 shows samples of SEM images at the microstructure level for fractured specimens at the two quasi-static rates and across a range of elevated temperatures. The effect of the temperature on the fracture mechanism by cavitation for the two strain rates of $0.0015 \mathrm{~s}^{-1}$ and $0.15 \mathrm{~s}^{-1}$ is noticeable. The greater the temperature, 
the greater is the observed voids density (i.e., damage) regardless of the applied strain rate. The damage was quantified by taking the average of up to five SEM images at the fractured surface.
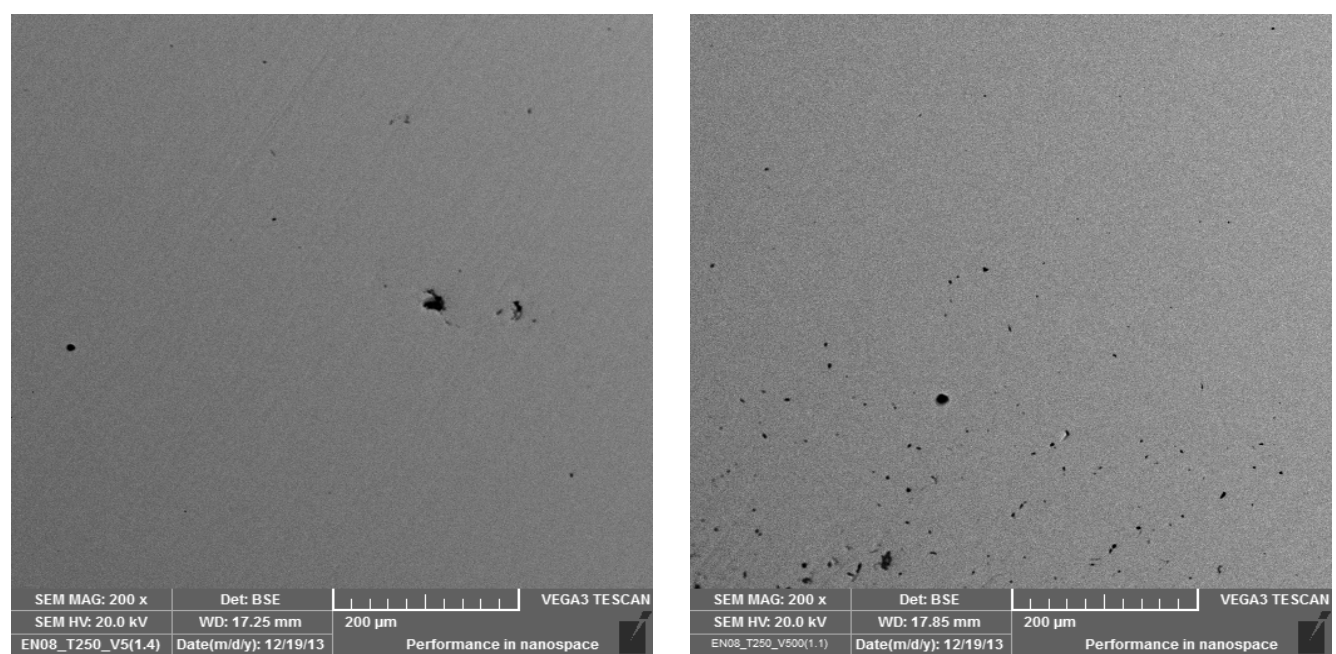

(a)
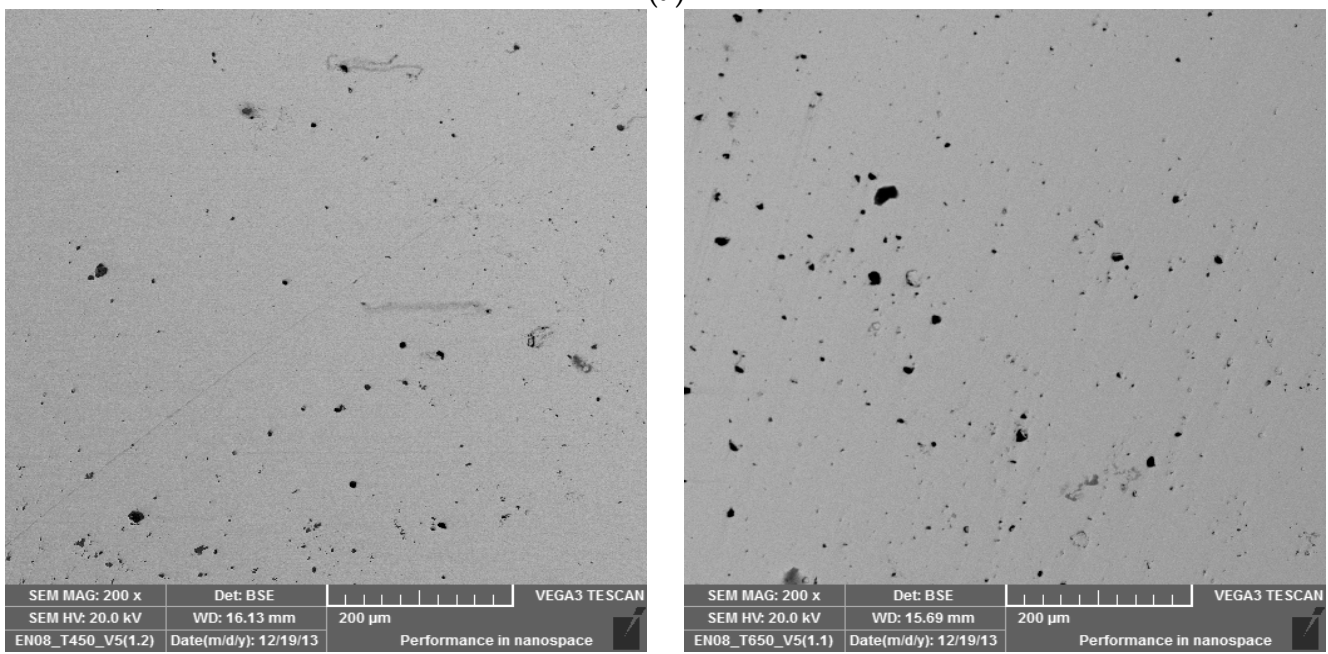

(b)
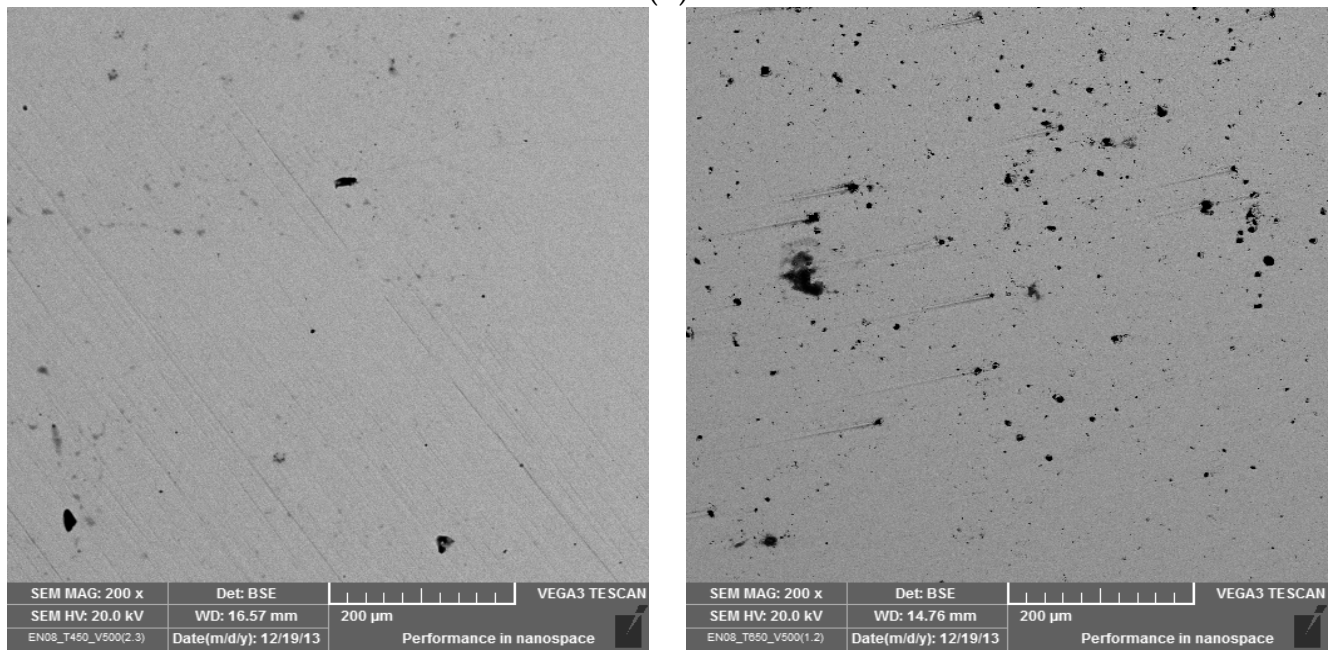

(c)

Figure 7. SEM images for polished samples at a temperature of (a) $523 \mathrm{~K}$, (b) $723 \mathrm{~K}$, (c) $923 \mathrm{~K}$, and at strain rates of $0.0015 \mathrm{~s}^{-1}$ (left) and $0.15 \mathrm{~s}^{-1}$ (right). 
The density of micro-cracks and voids were obtained from the SEM images by developing a post processing code using Matlab software (2017, Mathworks, Aztec, MA, USA). Figure 8 quantifies the results of the SEM images. The charts clearly illustrate the increase of damage with a strain rate and temperature. The results presented are used to identify the material constants for an energy-based damage model.

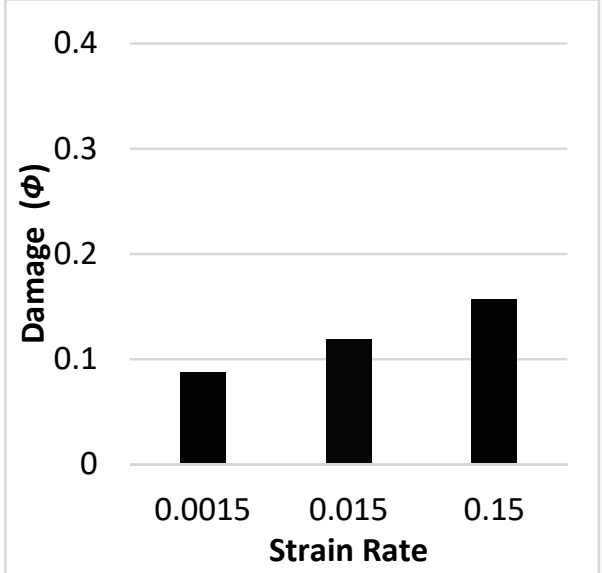

(a)

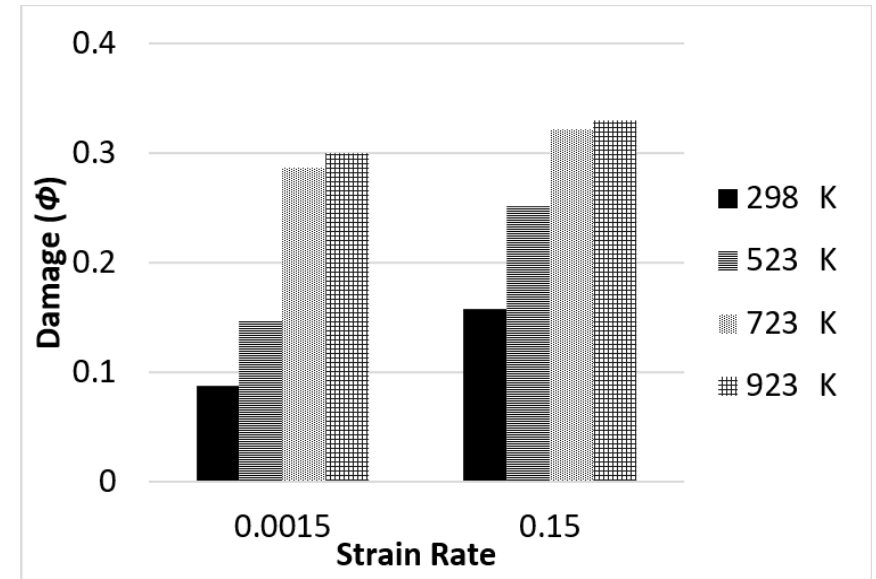

(b)

Figure 8. Average damage at (a) room and (b) high temperatures for different strain rates.

\section{Damage-Plasticity Description of EN08}

In order to describe the flow stress of EN08 steel, coupled damage-plasticity constitutive modeling is required. By integrating damage evolution into the constitutive relations, the mechanical behavior of steel can be accurately depicted. Note that the anisotropic behavior induced by damage is due to numerous micro-crack distributions and their growth within metals. Several damage models considering isotropic and/or anisotropic expressions for the damage variable have been proposed by many authors [23-27]. Although it is anisotropic in nature, assuming the damage isotropic is, in many cases, not far from reality [23]. The isotropic damage evolution can then be used to relate the undamaged and damaged states of the material [2].

\subsection{Energy-Based Damage Evolution Model}

Abed et al. [6] developed an energy-based model for describing the damage evolution in steel. This was done by using the principles of continuum damage mechanics. In this model, damage is described as the increase in the dissipated energy of a material with the model being the ratio of the dissipated energy to the total dissipated energy. The damage at fracture is also taken into consideration as the threshold damage value, which is both temperature-dependent and strain rate-dependent. Equation (1) illustrates the model below.

$$
\phi=\phi_{f}\left(\frac{U_{p}}{U_{P T}}\right)^{\alpha}
$$

where $\phi$ is the damage at the point of interest during deformation, $\phi_{f}$ is the damage at fracture obtained by SEM images (Figure 8), $U_{p}$ is the dissipated energy at the point of interest, $U_{P T}$ is the total dissipated energy, and $\alpha$ is a constant determining the damage evolution trend throughout deformation. The majority of steel has similar damage evolution trends. Therefore, $\alpha$ can be assumed to be 2.0. This is similar to the value retrieved by Abed et al. [6]. The dissipated plastic energy can be calculated by using Equation (2) with $\sigma$ and $\varepsilon$ being true stress and true strain, respectively.

$$
U_{p}=\int_{0}^{\varepsilon_{p}} \sigma d \varepsilon^{p}
$$


Figure 9 represents the damage evolution for the EN08 steel by considering all temperatures and strain rates. As the strain increases, the damage increases as well regardless of temperature. In general, the results seem to follow the same trend for most alloys [8]. For each loading combination, the damage effect is minimal at the initial stages and starts to grow on a higher scale as the plastic strains and, accordingly, the dissipated energy evolves, which leads to the degradation of the material.

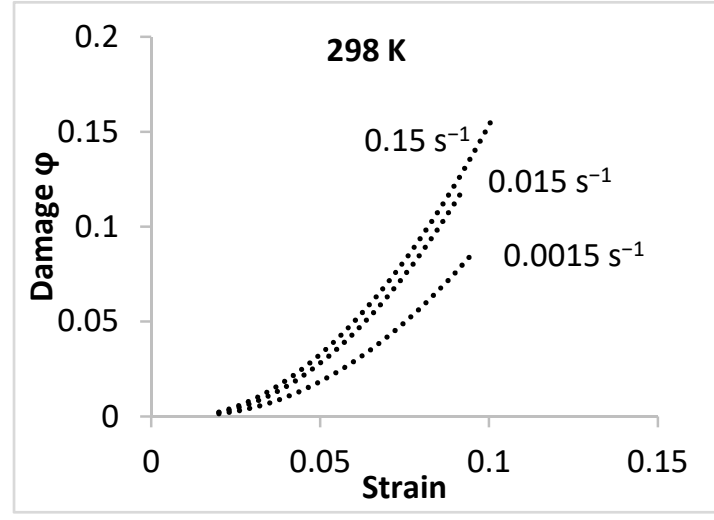

(a)

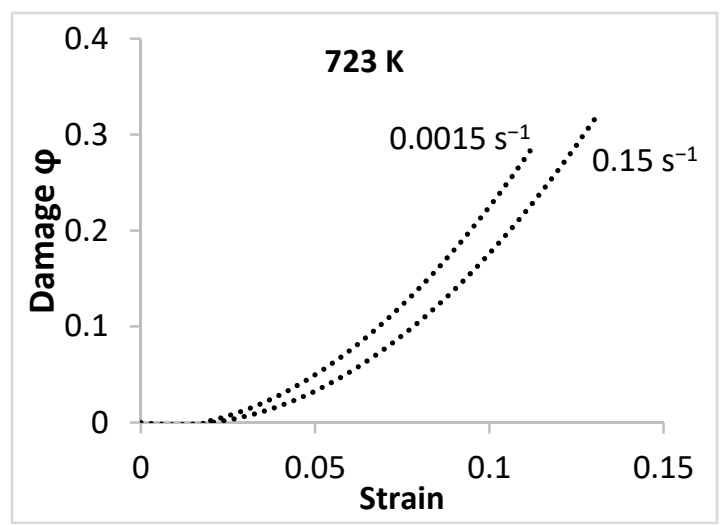

(c)

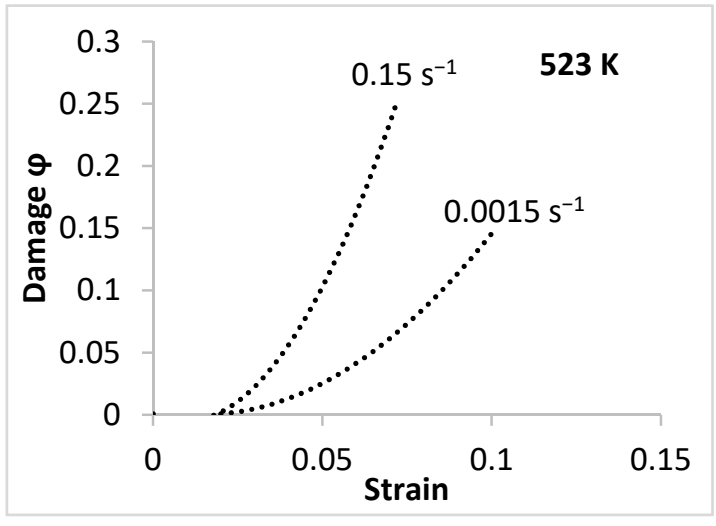

(b)

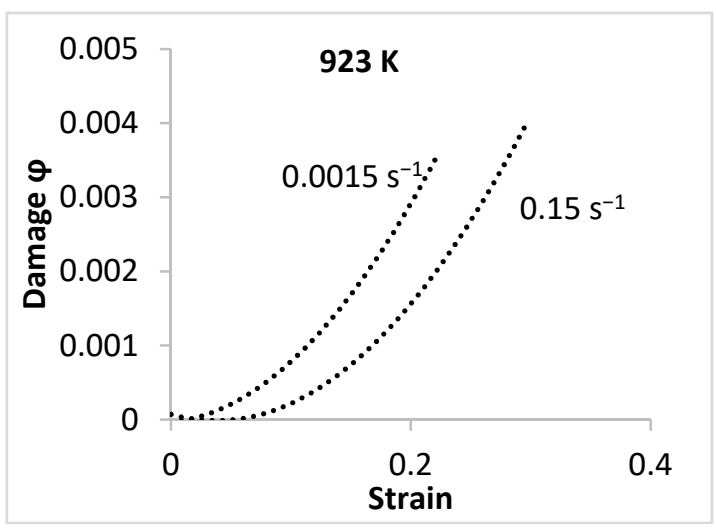

(d)

Figure 9. Damage $\phi$ evolution at quasi-static strain rates and temperatures of (a) $298 \mathrm{~K}$, (b) $523 \mathrm{~K}$, (c) $723 \mathrm{~K}$ and (d) $923 \mathrm{~K}$.

For the tensile test specimens, SEM images were taken from the fractured surface at the necking zone where higher strains achieved. However, for the drop-hammer tests, the specimens were not fractured (only compressed) and the only way to extract the images was by cutting the specimen in slides at the middle. However, this approach resulted in inaccurate images, which was highly affected by the cutting procedure. For this reason, the energy-based damage model was not applied to drop-hammer test specimens.

\subsection{Flow Stress Description of EN08}

The quasi static response of EN08 steel shows strong temperature dependency of the yield stress while strain hardening is slightly influenced by temperature. This means that the variation of the thermal stresses at a given strain rate appears mainly on the initial yielding where the strain hardening are nearly identical. Such behavior is known for ferrite steel. The thermal stress of ferrite steel is interpreted physically as the resistance of dislocation motion by the Peierls barriers provided by the lattice itself [19].

Constitute modeling is deemed necessary in order to understand quantitatively the deformation behavior of metals. Many constitutive models have been developed to describe the flow stress of metals 
and alloys when exposed to high temperatures and strain rates [28-32]. Experimental observation during the plastic deformation as well as the physical basis of the microstructure inside the material should be considered in developing any constitutive modeling of crystalline materials like steel. Dislocation interactions and evolutions play a crucial role in defining the flow stress of metals since each type has its own behavior coupled to a strain rate and temperature. One example of physically-based constitutive relationships is the VA model, which was derived based on thermal activation analysis and dislocation interaction mechanisms. The VA model was initially developed to describe the flow stress of pure metals by introducing different equations for different microstructures (i.e., BCC, FCC, and HCP) $[17,18,33]$ and then extended the flow stress for ferrite [19] and austenitic [22] steel as well as titanium alloys [34]. Such models require experimental data at a wide range of temperatures and strain rates to accurately identify its material constants, which are related to the microstructures physical quantities. For this reason, constitutive modeling of EN08 is not presented in this study since more thermal tests are required at higher strain rates. The temperature dependency becomes dominant at high strain-rate deformations where the adiabatic deformation produces significant temperature changes in ferrite steel [35-37].

\section{Concluding Remarks}

The thermo-mechanical behavior of EN08 steel, which is mainly used for manufacturing different mechanical parts, was investigated at different temperatures $(298 \mathrm{~K}, 523 \mathrm{~K}, 723 \mathrm{~K}$, and $923 \mathrm{~K})$ and strain rates $\left(0.0015 \mathrm{~s}^{-1}, 0.015 \mathrm{~s}^{-1}\right.$, and $\left.0.15 \mathrm{~s}^{-1}\right)$. Dynamic tests at intermediate strain rates were also conducted at room temperature by using a dynamic drop mass bench. With each test, the true stress-true strain curve was plotted in order to determine the behavior of the steel at different strain rates and temperatures. The Scanning Electron Microscopy (SEM) was utilized to analyze the damage caused relative to the varying test conditions. An energy-based damage model was employed by utilizing the SEM images to describe the damage evolution throughout the deformation process.

The thermomechanical response of EN08 followed a similar behavior of most ferrite steel at which the thermal stresses are mainly controlled by the yield stresses. The quasi-static test results at low and high temperatures revealed the typical degradation trend of the thermal stresses with a temperature increase. Dynamic strain aging (DSA) was also active at the lower quasi-static strain rate for a limited range of elevated temperatures. The strain hardening was found to be almost rate-independent at room temperature. However, the rate dependency behavior of the material slightly increased at higher temperatures. Furthermore, the SEM images of EN08 microstructures at fracture showed an increase in micro-cracks and voids with a strain rate and a temperature increase.

It should be mentioned that the application of this research outcome is limited to the loading conditions considered in the present experimental program. Any other scenarios intended to be implemented such as constitutive modeling shall consider further experimental tests and exploration.

Author Contributions: Farid Abed performed the results analysis and damage modeling and designed the experiments, Akrum Abdul-Latif conducted the experiments and contributed to the results analysis, and Ayatollah Yehia participated in data analysis and literature review. All three authors contributed to manuscript writing.

Funding: This research received no external funding.

Conflicts of Interest: The authors declare no conflict of interest.

\section{References}

1. Nemat-Nasser, S.; Guo, W.-G. Thermomechanical response of HSLA-65 steel plates: Experiments and modeling. Mech. Mater. 2005, 37, 379-405. [CrossRef]

2. Abed, F.; Saffarini, M.; Abdul-Latif, A.; Voyiadjis, G.Z. Flow stress and damage behavior of C45 Steel over a range of temperatures and loading rates. ASME J. Eng. Mater. Technol. 2017, 139. [CrossRef]

3. Guo, W.-G.; Nemat-Nasser, S. Flow stress of Nitronic-50 stainless steel over a wide range of strain rates and temperatures. Mech. Mater. 2006, 38, 1090-1103. [CrossRef] 
4. Abed, F.; ElSayegh, C.; Abdul-Latif, A. Thermo-Mechanical Description of AISI4140 Steel at Elevated Temperatures. In TMS Middle East-Mediterranean Materials Congress on Energy and Infrastructure Systems (MEMA 2015); Springer Chem: Basel, Switzerland, 2015; pp. 491-499. ISBN 978-3-319-48599-7.

5. Su, J.; Guo, W.; Meng, W.; Wang, J. Plastic behavior and constitutive relations of DH-36 steel over a wide spectrum of strain rates and temperatures under tension. Mech. Mater. 2013, 65, 76-87. [CrossRef]

6. Abed, F.H.; Al-Tamimi, A.K.; Al-Himairee, R.M. Characterization and modeling of ductile damage in structural steel at low and intermediate strain rates. J. Eng. Mech. 2012, 138, 1186-1194. [CrossRef]

7. Celentano, D.J.; Chaboche, J.-L. Experimental and numerical characterization of damage evolution in steels. Int. J. Plast. 2007, 23, 1739-1762. [CrossRef]

8. Darras, B.M.; Abed, F.H.; Pervaiz, S.; Abdu-Latif, A. Analysis of damage in 5083 aluminum alloy deformed at different strain rates. Mater. Sci. Eng. A 2013, 568, 143-149. [CrossRef]

9. Chae, D.; Koss, D. Damage accumulation and failure of HSLA-100 steel. Mater. Sci. Eng. A 2004, 366, $299-309$. [CrossRef]

10. Kumar, M.S.; Ragunathan, S.; Srinivasan, V. Effect of heat treatment on the fatigue behavior of EN8 steel. ARPN J. Eng. Appl. Sci. 2006, 11, 1326-1331.

11. Talukdar, P.; Sen, S.; Ghosh, A. The effect of high cycle fatigue damage on toughness of EN8 grade steel part ii. Mech. Eng. Robot. Res. 2013, 2, 232-239.

12. Haque, M.M.; Hashmi, M.S.J. Stress-strain properties of structural steel at strain rates of up to 105 per second at sub-zero, room and high temperatures. Mech. Mater. 1984, 3, 245-256. [CrossRef]

13. Singh, N.; Cadoni, E.; Singha, M.; Gupta, N. Dynamic tensile and compressive behaviors of mild steel at wide range of strain rates. J. Eng. Mech. 2013, 139, 1197-1206. [CrossRef]

14. Weinberger, C.R.; Boyce, B.L.; Battaile, C.C. Slip planes in bcc transition metals. Int. Mater. Rev. 2013, 58, 296-314. [CrossRef]

15. Duesbery, M.S.; Foxall, R.A.; Hirsch, P.B. The plasticity of the pure niobium single crystal. J. Phys. 1966, 27, 193-204. [CrossRef]

16. Šesták, B.; Blahovec, J. The temperature dependence of slip planes in Fe-3.4\% Si single crystals. Phys. Status Solidi 1970, 40, 599-607. [CrossRef]

17. Voyiadjis, G.Z.; Abed, F.H. Microstructural based models for bcc and fcc metals with temperature and strain rate dependency. Mech. Mater. 2005, 37, 355-378. [CrossRef]

18. Voyiadjis, G.Z.; Abed, F.H. Effect of dislocation density evolution on the thermomechanical response of metals with different crystal structures at low and high strain rates and temperatures. Arch. Mech. 2005, 57, 299-343.

19. Abed, F.H. Constitutive modeling of the mechanical behavior of high strength ferritic steels for static and dynamic applications. Mech. Time Depend. Mater. 2010, 14, 329-345. [CrossRef]

20. Wang, T.; Jonas, J.; Qin, H.; Yue, S. Effect of dynamic strain aging on the deformation and twinning behavior of a Mg-2Zn-2Nd alloy. Mater. Sci. Eng. A 2015, 645, 126-135. [CrossRef]

21. MacGregor, C.W.; Fisher, J.C. A velocity-modified temperature for the plastic flow of metals. J. Appl. Mech. 1946, 13, 11-16.

22. Abed, F.H.; Ranganathan, S.I.; Serry, M.A. Constitutive modeling of nitrogen-alloyed austenitic stainless steel at low and high strain rates and temperatures. Mech. Mater. 2014, 77, 142-157. [CrossRef]

23. Voyiadjis, G.Z.; Kattan, P.I. Advances in Damage Mechanics: Metals and Metal Matrix Composites; Elsevier: Oxford, UK, 1999; pp. 1-21.

24. Krajcinovic, D. Damage Mechanics. Mech. Mater. 1989, 8, 117-197. [CrossRef]

25. Baste, S.; Audoin, B. On internal variables in anisotropic damage. Eur. J. Mech. A Solids 1991, 10, 587-606.

26. Abdul-Latif, A.; Chadli, M. Modeling of the Heterogeneous Damage Evolution at the Granular Scale in Polycrystals under Complex Cyclic Loadings. Int. J. Damage Mech. 2007, 16, 133-158. [CrossRef]

27. Abdul-Latif, A.; Mounounga, T.B.S. Damage Deactivation Modeling under Multiaxial Cyclic Loadings for Polycrystals. Int. J. Damage Mech. 2009, 18, 177-198. [CrossRef]

28. Abed, F.; Makarem, F. Comparisons of constitutive models for steel over a wide range of temperatures and strain rates. J. Eng. Mater. Technol. 2012, 134. [CrossRef]

29. Goto, D.; Garrett, R.; Bingert, J.; Chen, S.-R.; Gray, G. The mechanical threshold stress constitutive-strength model description of HY-100 steel. Metall. Mater. Trans. A 2000, 31, 1985-1996. [CrossRef] 
30. Banerjee, B. The mechanical threshold stress model for various tempers of AISI 4340 steel. Int. J. Solids Struct. 2007, 44, 834-859. [CrossRef]

31. Voyiadjis, G.; Abed, F. Transient localizations in metals using microstructure-based yield surfaces. Model. Simul. Mater. Sci. Eng. 2006, 15, S83. [CrossRef]

32. Lee, Y.; Kim, B.; Park, K.; Seo, S.; Min, O. A study for the constitutive equation of carbon steel subjected to large strains, high temperatures and high strain rates. J. Mater. Process. Technol. 2002, 130, 181-188. [CrossRef]

33. Abed, F. On the differences of dynamic localisations between different types of metals. Int. J. Mater. Struct. Integr. 2010, 4, 215-237. [CrossRef]

34. Tabei, A.; Abed, F.H.; Voyiadjis, G.Z.; Garmestani, H. Constitutive modeling of Ti-6Al-4V at a wide range of temperatures and strain rates. Eur. J. Mech. A Solids 2017, 63, 128-135. [CrossRef]

35. Abed, F.H.; Makarem, F.; Voyiadjis, G.Z. Dynamic Localizations in HSLA-65 and DH-36 Structural Steel at Elevated Temperatures. J. Eng. Mater. Technol. 2013, 135, 021007. [CrossRef]

36. Makarem, F.S.; Abed, F. Nonlinear finite element modeling of dynamic localizations in high strength steel columns under impact. Int. J. Impact Eng. 2013, 52, 47-61. [CrossRef]

37. Nemat-Nasser, S.; Guo, W.-G. Thermomechanical response of DH-36 structural steel over a wide range of strain rates and temperatures. Mech. Mater. 2003, 35, 1023-1047. [CrossRef]

(c) 2018 by the authors. Licensee MDPI, Basel, Switzerland. This article is an open access article distributed under the terms and conditions of the Creative Commons Attribution (CC BY) license (http://creativecommons.org/licenses/by/4.0/). 